
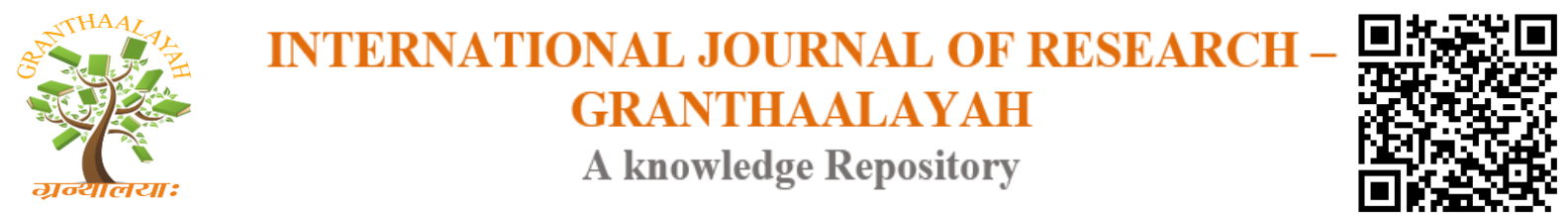

Management

\title{
HOW EFFECTIVE IS FUTURES AS AN INSTRUMENT OF HEDGING AGAINST PRICE RISK? - A STUDY BASED ON SPOT AND FUTURE PRICES OF GOLD
}

\author{
Muhammad Shafeeque A $\mathbf{P}^{\mathbf{1}}$, Thomachan K $\mathbf{T}^{\mathbf{2}}$ \\ ${ }^{1}$ MA Economics, Department of Economics, St.Joseph's college, Devagiri, Kozhikode, INDIA \\ ${ }^{2}$ Associate Professor, Department of Economics, St.Joseph's college, Devagiri, Kozhikode,
} INDIA

DOI: https://doi.org/10.29121/granthaalayah.v4.i9.2016.2548

\section{ABSTRACT}

This paper examines the role of commodity futures market as an instrument of hedging against price risk. Hedging is the practice of offsetting the price risk in a cash market by taking an opposite position in the futures market. By taking a position in the futures market, which is opposite to the position held in the spot market, the producer can offset the losses in the latter with the gains in the former. Both static and time varying hedge ratios have been calculated using VECM-MGARCH model. Variance of return from hedge portfolio has been found to be low. Further hedging effectiveness has been observed to be around $12 \%$.

Keywords:

Hedge Ratio, Hedge effectiveness, Unit Root, Cointegration, VECM-MGARCH.

Cite This Article: Muhammad Shafeeque A P, and Thomachan K T, "HOW EFFECTIVE IS FUTURES AS AN INSTRUMENT OF HEDGING AGAINST PRICE RISK? - A STUDY BASED ON SPOT AND FUTURE PRICES OF GOLD” International Journal of Research Granthaalayah, Vol. 4, No. 9 (2016): 143-150.

\section{INTRODUCTION}

The financial development of any nation depends on the efficiency and soundness of its exchange markets. It is one of the important segments in promoting and sustaining economic growth by facilitating and encouraging the movement of funds from savers to investment. The exchange market in India has played a vital role because it does "follow the sun around the globe" i.e. they function 24 hours a day with the fastest possible communication. It is crucial to the functioning of an economy to transfer fund from surplus to deficit unit to ensure the welfare of well-being.

The business in foreign exchange markets in India has shown a steady increase as a consequence of increase in the volume of foreign trade of the country, improvement in the communication 
system and greater access to the international exchange markets. Since the policy of Reserve Bank has been decentralized, the exchange operations and development broader exchange markets. Spot and future contracts are two important types of transaction conducted in exchange markets. In spot market, the delivery of the foreign exchange has to be made 'on the spot'; usually within two days. The exchange rate at which the transaction takes place is called the spot rate. The spot exchange rate is determined by immediate market demand and supply of foreign exchange. In future market, the exchange is bought and sold for delivery at a future date, an agreed rate today.

It is to be rightly said that India is a commodity based economy. In the commodity market, gold has a unique relevance. It has been a pillar of tangible, storable and transportable wealth. It is the core component of Indian culture, both social and financial. In the times of crisis also, it has proved to be most accessible and safest asset for investors. But continuous fluctuations in its price make a weird situation in the market. So persons who deal in gold price have risk element. The risk of price variability of gold can be managed by the mechanism of hedging. Hedging is an important factor influencing the future price of gold. The main purpose and benefit of hedging is to minimize possible revenue losses associated with adverse cash price changes.

The hedging effectiveness of future index of gold has been extensively investigated in recent years using the portfolio approach to hedging and the associated Minimum Variance Hedge Ratio (MVHR). The introduction of future contracts offers to market participants the opportunity to manage the market risk of their portfolios without changing the portfolio composition. The effectiveness of a hedge becomes relevant only in the event of a significant change in the value of the hedged item. A hedge is effective if the price movements of the hedged item and hedging derivative roughly offset each other.

In last five years Indian future markets have grown rapidly. Indian future markets for gold are going through many ups and downs and allegations of speculative activity which become popular in press. However there is a need for systematic investigation of Indian future market for gold to assess its hedge effectiveness to manage risk element since future markets for gold has not been received sufficient attention on the estimation of hedge ratio and hedge effectiveness. So this particular study is an attempt to investigate the hedging effectiveness of gold price in determining spot and future price in a developing country like India and it would help to protect the interest of traders.

\section{LITERATURE REVIEW}

Most of the studies investigate the hedging effectiveness of gold price index futures related to developed countries like USA, UK, Japan etc. Still many recent researches have been found in developing countries like India and China as well.

Thompson and Bond (1987) in their study extended the analysis of optimal hedging decisions to account for the exchange rate uncertainties faced by off shore traders dealing on U.S. futures exchanges. Statistical findings indicate that exchange rate risk may affect commodity hedging decisions in situations where exchange rates and commodity prices are perceived to interact with one another over time. 
Holmes (1996) tried to assess the appropriate econometric technique when estimating optimal hedge ratios of the FTSE-100 stock index by applying a GARCH $(1,1)$ as well. He showed that in terms of risk reduction a hedge strategy based on MVHRs is estimated using OLS outperforms optimal hedge ratios that are estimated by using more advanced econometric techniques such as an ECM or a GARCH $(1,1)$ approach.

According to Pennings and Leuthold (1999) hedging effectiveness is related to trading volume and this relationship is more prominent when the hedging effectiveness takes market depth risk into account. Having evaluated the hedging effectiveness by taking into account basis risk and market depth risk and analyzing the overall risk reduction capacity of the derivative contract, they conclude that hedging effectiveness is an important determinant in explaining the derivatives' contract volume.

Silvapulle and Moosa (1999) in their study examine the relationship between the spot and futures prices of WTI crude oil using a sample of daily data. Linear causality testing reveals that futures prices lead spot prices, but nonlinear causality testing reveals a bidirectional effect. These results suggest that both spot and futures markets react simultaneously to new information.

Narender L. Ahuja (2006) expressed that the futures and options trading help in hedging the price risk and also provides investment opportunity to speculators who are willing to assume risk for a possible return. They can also help in building a comparative edge and enable businesses to smoothen their earnings because non-hedging of the risk would increase the volatility of their quarterly earnings.

Ramakrishna and Jayasheela (2009) examine the hedging effectiveness of Nifty futures using the Ordinary Least Squares (OLS) technique. Empirical results show that the volatility of the Nifty spot index has been reduced after the introduction of the futures trading, though the percent reduction of volatility is meagre.

\section{HEDGE RATIO AND HEDGING EFFECTIVENESS}

The ratio of the number of units of the futures asset that are purchased relative to the number of units of the spot asset is known as the hedge ratio. Since risk is usually measured as the volatility of portfolio returns, an intuitively possible strategy might be to choose that hedge ratio which minimizes the variance of the returns of a portfolio containing the spot and future position; this is known as the optimal hedge ratio.

The return on an unhedged and a hedged portfolio can be written as:

$R_{u}=S_{t+1}-S_{t}$

$R_{H}=\left(S_{t+1}-S_{t}\right)-H\left(F_{t+1}-F_{t}\right)$

Variance of an unhedged and a hedged portfolio are:

$\operatorname{Var}(U)=\sigma_{S}^{2}$

$\operatorname{Var}(H)=\sigma_{s}^{2}+H^{2} \sigma_{f}^{2}-2 H \sigma_{s f}$ 
Where $F_{t}$ and $S_{t}$ are natural logarithm of spot and future prices, $H$ is the hedge ratio, $R_{H}$ and $R_{U}$ are returns from unhedged and hedged portfolio, $\sigma_{s}$ and $\sigma_{f}$ are standard deviation of the spot and future returns and $\sigma_{s, f}$ is the covariance. Optimum hedge ratio is calculated by minimizing (4) with respect to $H$ :

$$
H=\frac{\sigma_{s, f}}{\sigma_{f}^{2}}
$$

Hedging effectiveness is defined as the ratio of the variance of the unhedged position minus variance of the hedged position over the variance of unhedged position:

$\operatorname{Effectiveness}(E)=\frac{\operatorname{Var}(U)-\operatorname{Var}(H)}{\operatorname{Var}(U)}$

The optimum hedge ratio given in (5) is time invariant in the sense that its value remains constant over time. An alternative is the dynamic hedge ratio, the value of which is time varying. The time varying hedge ratio is calculated as:

$H_{t}=\frac{h_{s f, t}}{h_{f f, t}}$

Where $h_{f f}$ is the conditional future variance and $h_{s f}$ is the covariance between current and future prices.

\section{DATA AND METHODOLOGY}

The study is based on daily spot and future prices of gold for the period June 1, 2010 to May 31, 2015. Both series are used in log form and denoted as "LOG SPOT" and "LOG FUTURE".

A number of methodological issues should be resolved when time series data is used for empirical analysis. We outline below the methodology adopted in the present study to estimate hedge ratio and hedging effectiveness.

\section{1) Testing for Unit Roots:}

An important issue that has received much attention from time series econometricians in recent times when using time series data for analysis is the phenomenon of nonstationarity. Regressing one nonstationary time series on another give rise to the problem of spurious regression i.e., absence of any meaningful relationship between variables. To guard against the possibility of spurious regression, a number of testing procedures are available to determine stationarity/nonstationarity of time series variables. The present study utilizes the Dickey - fuller test in augmented form to check stationarity. The test is available in three forms depending on no intercept, intercept, intercept and trend in the data. The test in its most general form is:

$$
\Delta Y t=\mu+\gamma Y t-1+\sum_{i=1}^{p} \Delta Y t-i+\varepsilon t
$$




\section{2) Johansen Cointegration Test:}

Several methods are available to estimate constant and dynamic hedge ratio and hedging effectiveness. The present study uses Vector autoregressive (VAR)/vector error correction (VECM) methodology to estimate constant hedge ratio. If the variables are stationary VAR in the level of the series is appropriate for the estimation of hedge ratio. If the variables are nonstationary and not cointegrated VAR in first differences is used to avoid the probem of spurious regression. If the variables are nonstationary but cointegrated VECM framework will be appropriate for the estimation of constant hedge ratio.

The most widely used procedure for determining the existence of cointegration among a set of nonstationaryI(1) variables is the Johansen procedure. In the Johansen framework, the first step is the estimation of $\mathrm{a} \mathrm{p}^{\text {th }}$ order VAR in $\mathrm{k}$ variables:

$Y t=\Pi 1 Y t-1+\Pi 2 Y t-2+\cdots+\Pi p Y t-p+\varepsilon t$

Where Yt is a (kx1) vector of nonstationaryI(1) variables, $\pi i$ is an (nxn) matrix of parameters and $\varepsilon t$ is an $(\mathrm{nx} 1)$ vector of innovations.

If there is cointegration between variables in $\mathrm{Yt}$, equation (9) can be reparameterised into VECMof the following form:

$\Delta Y t=\Pi Y t-1+\Gamma 1 \Delta Y t-1+\Gamma 2 \Delta Y t-2+\cdots+\Gamma p-1 \Delta Y t-(p-1)+\varepsilon t$

Where $\Pi=\Pi 1+\Pi 2+\cdots+\Pi p-I$ and

$\Gamma i=-(\Pi i+1+\Pi i+2+\cdots+\Pi p) ; i=1,2 \ldots p-1$

Johansen cointegration test is based on two test statistic namely trace statistic and $\lambda$ max statistic based on the Eigen values of the П matrix from equation (11) namely;

$$
\begin{aligned}
& \lambda_{\text {trace }(r)}=-T \sum_{i=r+1}^{k} l_{n}\left(1-\hat{\lambda}_{i}\right) \\
& \lambda_{\max (r, r+1)}=-T l_{n}\left(1-\hat{\lambda}_{r+1}\right)
\end{aligned}
$$

Hedge ratio and hedging effectiveness are calculated from the error terms of spot and future prices in equation (10).

\section{3) VECM-MGARCH Model}

Many time series exhibits time varying variance. To model such time varying variability, autoregressive conditional heteroscedasticity $(\mathrm{ARCH})$ developed by Robert Engel and its extension generalized autoregressive conditional heteroscedasticity (GARCH) developed by Bollerslev are employed.

If $\mathrm{ARCH}$ effect is present in the spot and future returns, estimation of constant hedge ratio and hedging effectiveness may be inappropriate. Estimation of time varying hedge ratio and hedging effectiveness will be more appropriate in the presence of $\mathrm{ARCH}$ effect. The VECM-MGARCH model considers the ARCH effect of the time series and calculates the time varying hedge ratio. We use constant conditional correlation (CCC) model to estimate time varying hedge ratio. First, errors from the VECM model are obtained and then the errors are modeled as a CCC-bivariate 
GARCH. Variances of spot and future prices and covariance between both are calculated using the following equations:

$h_{s, t}=\alpha 1+\alpha 2 \varepsilon_{s, t-1}^{2}+\beta 1 h_{s, t-1}$

$h_{f, t}=\gamma 1+\gamma 2 \varepsilon_{f, t-1}^{2}+\lambda 1 h_{f, t-1}$

$h_{s f, t==} \rho\left(h_{s, t *} h_{f, t}\right)$

Where $h_{s, t}$ is the conditional spot variance at time $\mathrm{t}, h_{f, t}$ is the conditional future variance, $h_{s f, t}$ is covariance and $\rho$ is the constant conditional correlation. Time varying hedge ratio is

\section{RESULTS AND DISCUSSION}

\section{1) Unit Root Test}

Both spot and future price series of gold has been tested for stationarity using Augmented Dickey Fuller test in level and first differences. The test result clearly indicates that both series are nonstationary in levels but stationary in first differences.

Table 1: Unit root test for spot and future prices

\begin{tabular}{|l|l|l|}
\hline Variables & Levels & First Difference \\
\hline LOG SPOT & $-1.813263(0.6981)$ & $-32.8396(0.0000)^{* *}$ \\
\hline LOG FUTURE & $-1.932365(0.6369)$ & $-34.9851(0.0000)^{* *}$ \\
\hline
\end{tabular}

Figures in brackets are $\mathrm{P}$ values.

** indicates significance at $1 \%$ level

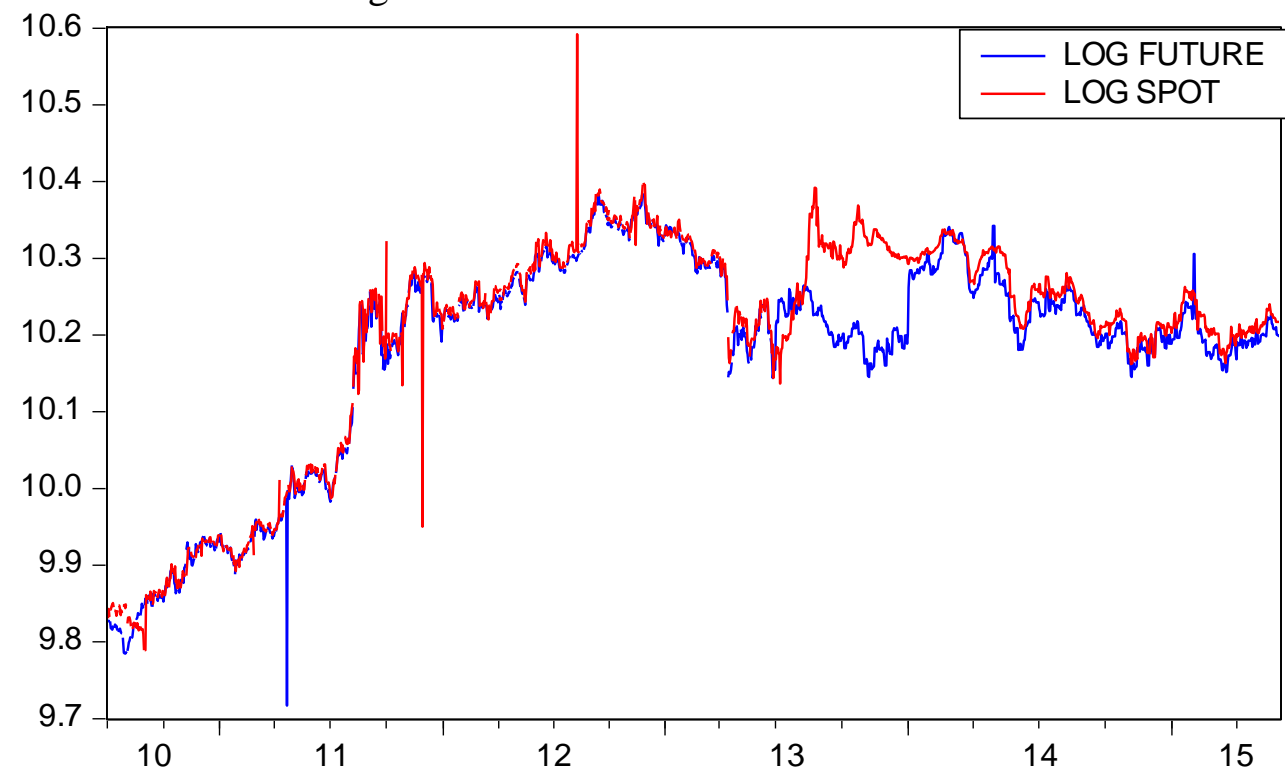

\section{2) Cointegration Analysis.}

Cointegration between spot and future price has been tested using Johansen cointegration analysis. Both $\lambda$ maxand $\lambda$ trace statistics indicate the existence of one cointegrating relationship between spot and future prices. 
Table 2: Testing for cointegration between spot and future prices

\begin{tabular}{|l|l|l|}
\hline $\begin{array}{l}\text { Hypothesized } \\
\text { No of CE(s) }\end{array}$ & $\lambda_{\text {trace }}$ & $\lambda_{\max }$ \\
\hline None & $21.15785(.0063)^{*}$ & $14.82245(.0408)^{*}$ \\
\hline At most 1 & $6.3354(.0718)$ & $4.89654(.0925)$ \\
\hline
\end{tabular}

Figures in brackets are $\mathrm{P}$ values

* denotes significance at $5 \%$ level

\section{3) Constant Hedge Ratio Using VECM Estimates.}

Since the existence of a cointegrating relationship has been established using Johansen cointegrating rank test, the entire model has been reformulated as a VECM model and the residuals are obtained. Lag length has been selected using information criteria. The residuals from the model are used to calculate hedge ratio and hedging effectiveness.

$$
\begin{aligned}
& \text { Optimum Hedge Ratio }(H)=\frac{\sigma_{s, f}}{\sigma_{f}^{2}}=0.22 \\
& \text { Effectiveness }(E)=\frac{\operatorname{Var}(U)-\operatorname{Var}(H)}{\operatorname{Var}(U)}=0.12
\end{aligned}
$$

\section{4) Dynamic Hedge Ratio using VECM - MGARCH model}

We test the residuals from the VECM model for ARCH effect and find that both series exhibit significant ARCH effect. The presence of ARCH effect in the series confirms the necessity of M -GARCH modeling to estimate time varying hedge ratios. Using the conditional variances and covariance obtained, dynamic hedge ratio has been estimated. Average dynamic hedge ratio and hedging effectiveness are also calculated.

Average Time varying Hedge Ratio $\left(H_{t}\right)=\frac{h_{s f, t}}{h_{f f, t}}=0.28$

Average Dynamic Hedging Effectiveness $(E t)=\frac{\operatorname{Var}(U)-\operatorname{Var}(H)}{\operatorname{Var}(U)}=0.18$

\section{CONCLUSION}

This paper investigated hedging effectiveness of gold price in spot and future contract markets for a period of five years of daily data from June 1st, 2010 to May 31st, 2015. Both series are used in log form and denoted as "LOG SPOT" and "LOG FUTURE". The Augmented Dickey Fuller Unit Root test concluded that spot and future price series of gold are non-stationary but stationary in first differences. The Johansen's co-integration test established the existence of long run relationship between spot and future prices. Hedge ratio and hedging effectiveness has been calculated using the residuals obtained from $\mathrm{CCC}$-bivariate GARCH model. Static and time varying hedge ratios are respectively 0.22 and .028 .Static and dynamic hedging effectiveness are respectively 0.12 and 0.18 . Thus hedging effectiveness is found to be low suggesting that gold futures are not a very effective hedging device to mitigate the risks associated with gold price fluctuations. 


\section{REFERENCES}

[1] Ahuja, Narender, L. (2006). "Commodity Derivatives Market in India: Development, Regulation and Future Prospects”. International Research Journal; ISSN, 1450-2887, Issue 2.

[2] Bond, Gary, E. and Thompson, Stantey R. (1985), "Risk Aversion and the Recommended Hedging Ratio”, American Journal of Agricultural Economics, Vol. 67, No.4, pp. 870872.

[3] Gujarati Damodar N. \&Sangeetha, "Basic Econometrics”, Fourth Edition, McGraw Hill Pvt. Ltd., New Delhi, 2011.

[4] Johansen, S. "Statistical Analysis of Cointegrating Vectors", Journal of Econometric Dynamics and Control, Vol: 12, 231-54, 1998.

[5] Kawai, Mashiroy (1983), "Spot and Futures Prices of Nonstorable Commodities under Rational Expectations”, The Quarterly Journal of Economics, Vol.98, No.2, pp.235-254.

[6] Ramakrishna, R. and Jayasheela (2009), "Impact of Futures Trading on Spot Market and Price Discovery of Futures Market”, Indian Journal of Agricultural Economics, Vol.64, No.2, pp. 372-384.

[7] Walter Ender, “Applied Econometric Time Series”, 4th edition, (2014). 